into the ionosphere far above the highest meteorological soundings, and I found there a most unexpected relationship with the day-to-day barometric readings.

At the present time it seems to me that sudden or temporary changes of the quality of solar radiation, acting directly upon the highest levels of our atmosphere, must react indirectly upon atmospheric circulation and a polar overcharge of pressure, which is discharged by waves, by baroterons.

Smithsonian Institution, Washington, D.C.

\title{
ERRORS IN THE SYNOPTIC WEATHER-CHARTS WHICH COVER THE GREENLAND REGION
}

William H. Hobbs and Ralph L. Belknap

Greenland is a very large island with the outline of a human left ear. Its length in a northsouth direction is about 1,600 nautical or 1,800 English miles, and its average breadth about 600 nautical or 750 English miles. Its area is comparable roughly with that part of the United States which is east of the Mississippi River. Save for this elongated outline, Greenland's model is that of an old-fashioned hunting-case watch--it is a flattened dome with increasingly steep outward slopes upon its borders. With exception of a marginal ribbon of land usually less than 50 miles in width, Greenland is blanketed by a glacier which everywhere forms its surface (see Fig. 1).

Though the maximum elevation of this glacier-surface is usually given as around 10,000 feet, its altitude is actually unknown, for this assumed elevation is based on aneroid recordings made during transections. (Barometer-readings are determined largely by two factors, altitude and weather-condition, but the decrease in atmospheric pressure in penetration of the island has here been ascribed wholly to altitude. The centrifugally directed winds of Greenland indicate that the altitudes given by the maps are too low by many hundreds of feet. That this is so is further indicated by the failure of the meteorological pattern to accord with the assumed topographical one. Further evidence is possibly supplied by the crashes of Allied planes of the Ferry Command that had used the maps to determine safe flying-altitudes.) The Wegener Greenland Expedition of 1929-31 ran a line of precise levels from the west coast in latitude $71^{\circ}$ to their station of Mid-Ice, but the result has not been published and still remains a German military secret.

The fixed glacial anticyclone which at all times overlies Greenland [see 1 of "References" at end of paper] is modeled on the form of an hour-glass, a model elsewhere realized on our planet only above the Antarctic glacier of the same continental blanketing type. The Antarctic anticyclone is, however, roughly centered near the South Pole, and cyclones circle about it in a direction from west to east in continuous procession within the zone of the "roaring forties" and the "screetching fifties and sixties" (of latitude).

Greenland is centered in an eccentric position $\left(73^{\circ}\right.$ north) to the Earth's northern pole and the glacial anticyclone above it thus lies athwart the paths of the more northerly cyclones arriving from the southwest. The southerly cyclone tracks by-pass Cape Farewell at the southern tip of Greenland, and they continue eastward into the Icelandic Low or are deflected northeastward through the Greenland Sea.

All air-masses which arrive from western quarters and are able to advance into the Greenland Area are above the level of 3,000 meters where they make the transit of the west coast. (From balloon-observations made at the three stations of the University of Michigan located at Ivigtut in latitude $61^{\circ}$, at Mount Evans near latitude $67^{\circ}$, and at Peary Lodge near latitude $74^{\circ}$; set Reports of the Greenland Expeditions of the University of Michigan, v. 1 and v. 2.) When these currents had arrived about 25 English miles inland, where the glacier-surface was nearly 1,000 meters higher, this ceiling to the outward-blowing winds was found to be about 1,000 meters higher, or at the 4,000-meter level [2] (see Fig. 2).

As a result of coordinated observations by American, British, and German expeditions made in 1930-31 and in 1932-33, it has now been definitely determined that the cyclones which arrive at the Greenland west coast are halted there and pass up Davis Strait to be dissipated on reaching the Polar Basin, the oceanic area north of $80^{\circ}$ north [3]. During these two periods 1930-31 and 1932-33 (Second International Polar Year), for the first times in history the number and reliability 


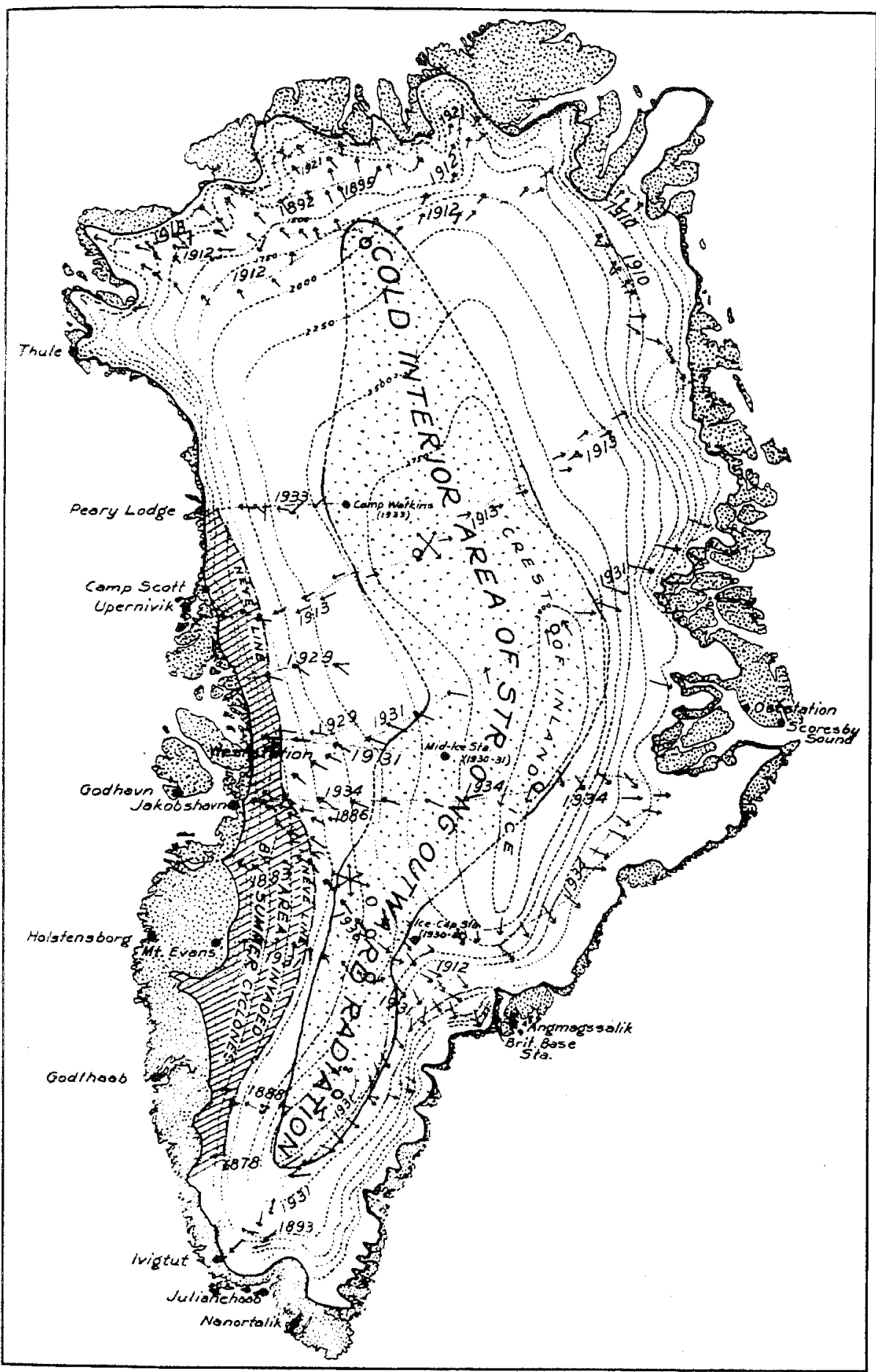

Fig. 1--Map of Greenland which sets forth topographical model on basis of aneroid readings, and the meteorological model of the fixed glacial anticyclone (Note the lack of accord) 


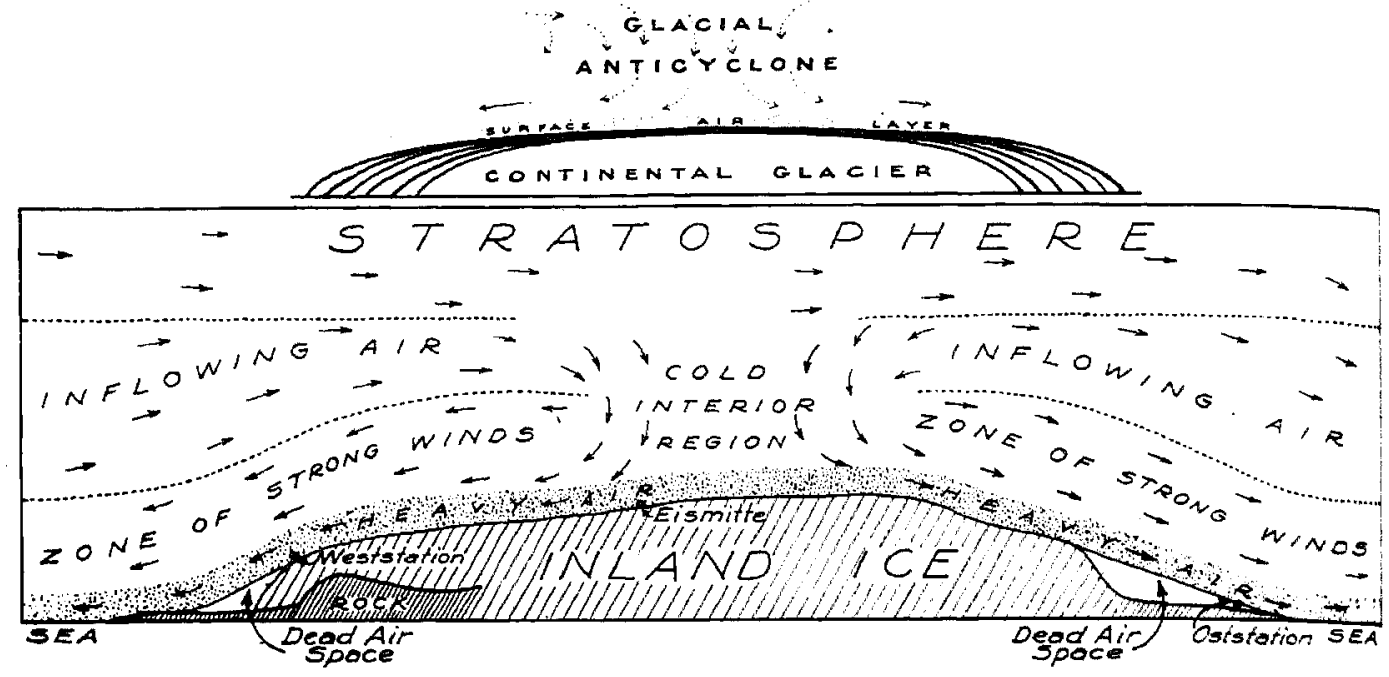

Fig. 2--Model of the Greenland glacial anticyclone (upper) from characteristics of existing glaciers (p.288), 1911, and model of same (lower) as of 1944, which takes account of subsequent research, and so shows sharp delimitation of cold interior region, definite outward sloping ceiling of layer of outward blowing winds, and relatively thin surface layer of heavier air at bottom of these outblowing air-currents

of the meteorological stations of Greenland have been sufficient for following the paths of cyclones in its vicinity (see Fig. 3). The official Danish coastal weather-stations, 12 in number and generally of second and third grade, supply reliable recordings of pressure, but, located as they have been in the bottoms of fjords, their recordings of force and direction of wind have been not only unreliable but most misleading [4]. Six of this number, all in south Greenland, have been supplied with radio and have therefore been used in making the synoptic weather-charts issued regularly by both the Deutsche Seewarte at Hamburg and the British Air Ministry.
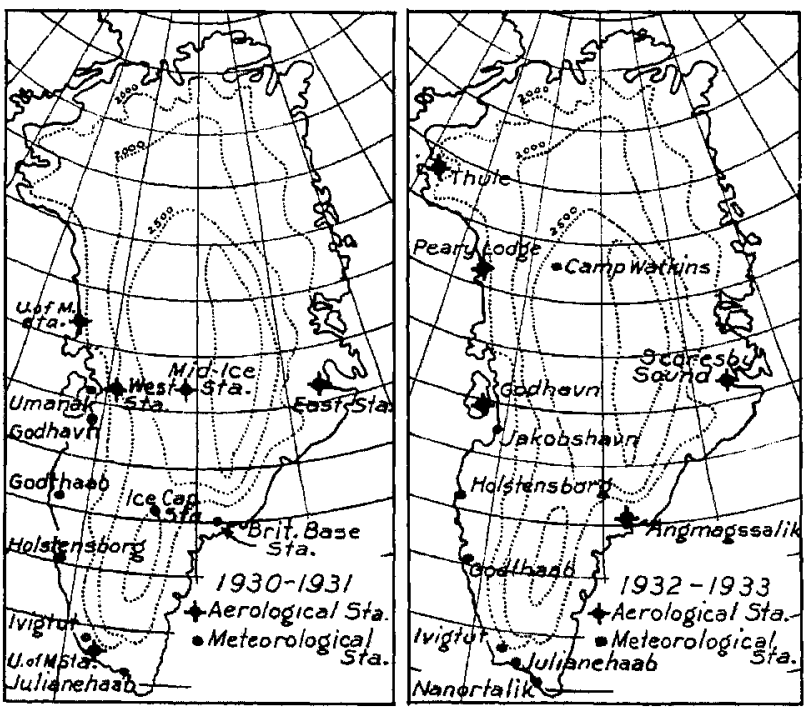

Fig. 3--Maps to show location of meteorological and aerological stations in Greenland in 1930-31 and in 1932-33 


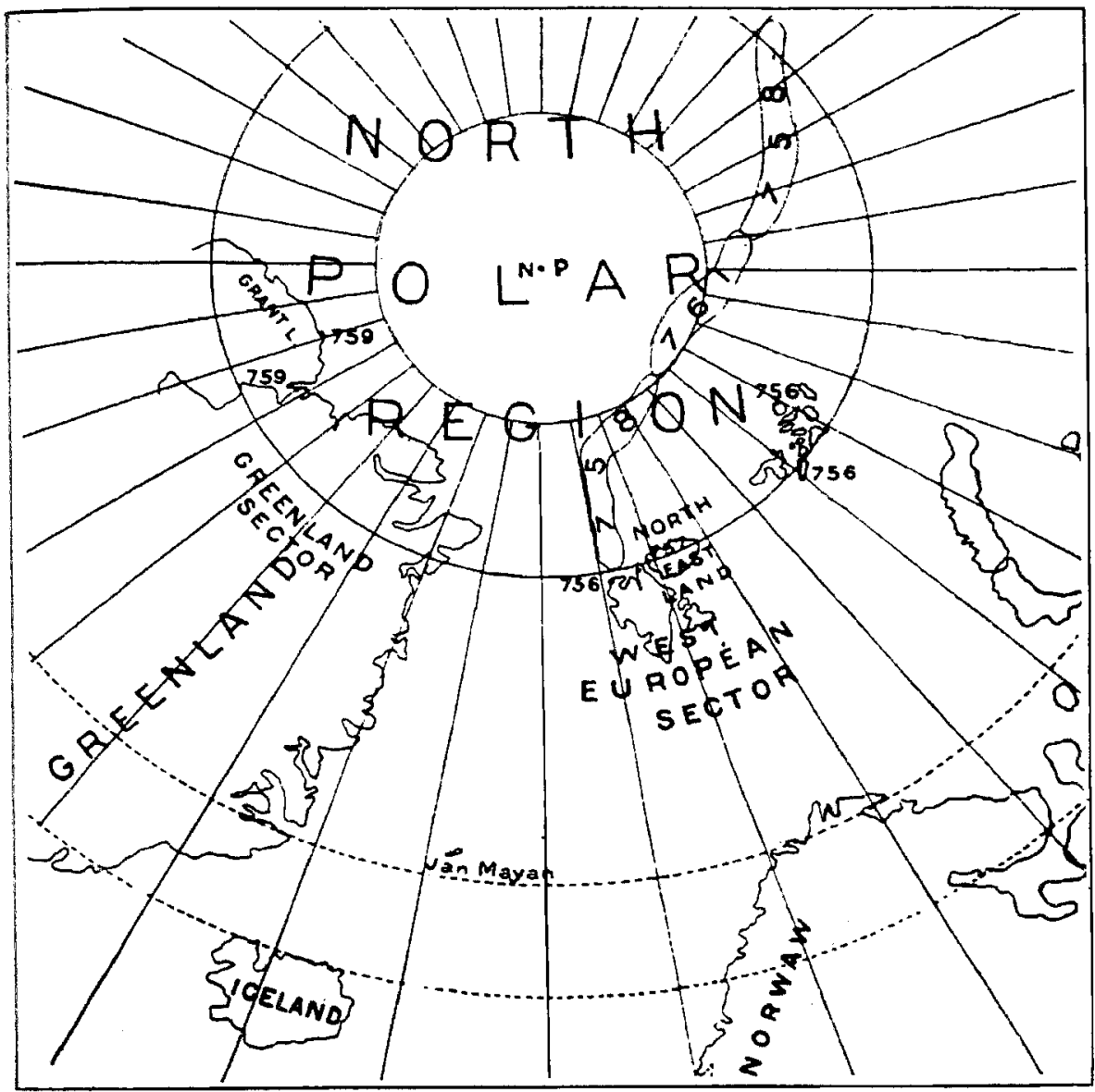

Fig. 4--Map to show average annual air-pressures in millimeters of mercury within Polar Basin, based on exploration before 1926, from The glacial anticyclones (Fig. 50, p.149)

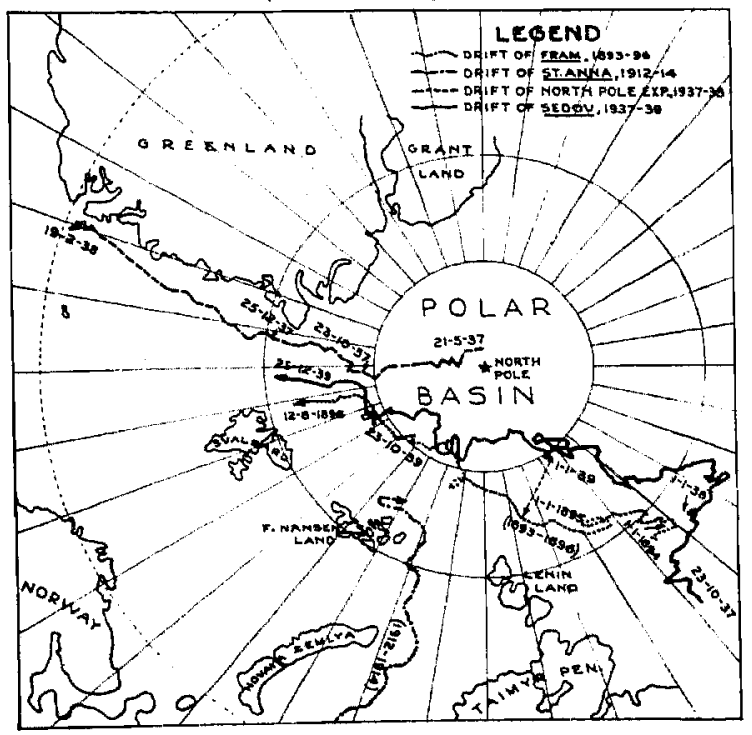

Fig. 5--Map of Polar Basin to show recent Soviet exploration 


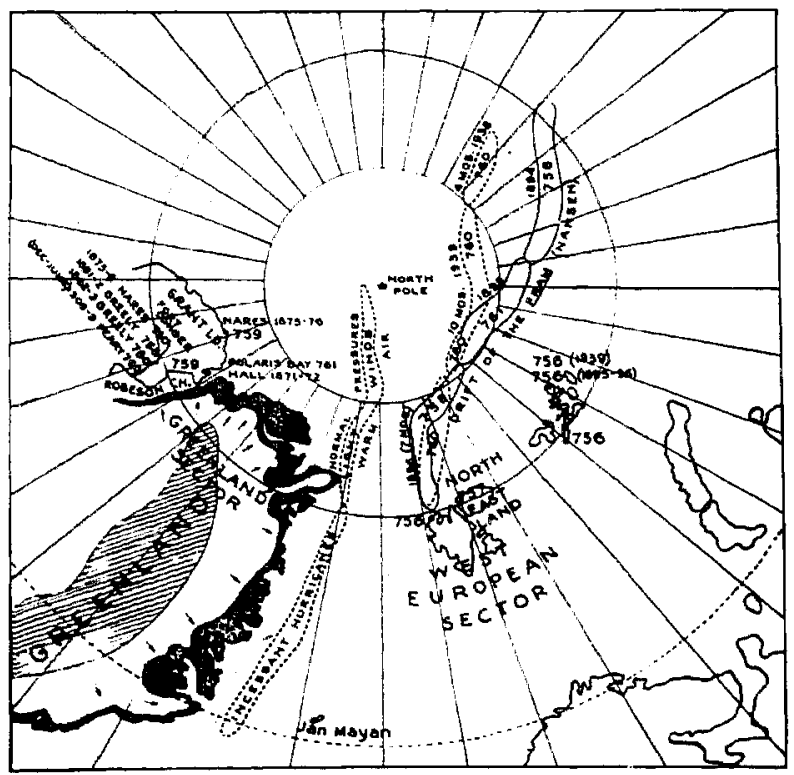

Fig. 6--Map to show meteorological conditions over Polar Basin

The inner core of the descending air-currents of the Greenland anticyclone is sharply delimited on all sides by a sudden rise in air-temperatures and by an equaliy sharp fall in daily temperature-range. The force of the centrifugally directed air-currents outside this central core varies between calms and winds of hurricane velocities (100 to 150 or more miles per hour). These fierce katabatic winds extend far out over the sea beyond the coasts of Greenland with the same general direction though with dextro-rotary deviation due to rotation of the Earth.

Official weather offices which issue daily synoptic charts inclusive of the Greenland Area (see, for example, those issued I.y the British Air Ministry), have long persisted in ignoring the abovedescribed conditions, despite the fact that these have been known in greater part for 2 quarter of 2 century, and they continue to draw the isobars across Greenland exactly as though it were a quite normal expanse of sea. The North Polar Basin, the Arctic Ocean north of $80^{\circ}$ north, has also been treated by them as though it were at all times an area of high atmospheric pressure and low airtemperatures. Yet, as long ago as 1926, the senior author of this paper showed on the basis of suct exploration as had then been made that the Polar Basin appeared to be the unique large area of average normal atmospheric pressure upon our planet [5] (see Fig. 4) and that it is far from being an area of extreme cold. (In the summer the air-temperatures are often excessively warm, and in the winter much warmer than those over central Siberia or central British America. Then on the Arctic coasts, the air-temperature drops with scutherly winds, and rises with wind from the Polar Basin.)

The recent Soviet exploration within the North Polar Basin (North Pole Station, May 21, 1937, to February 19, 1938; drift of the Sedov 1938 and 1939, and that of the Santa Anna in 1814) has confirmed and extended greatly the earlier evidence (see Fig. 5). The full meteorological report of this work will probably not be published until the termination of hostllities in Europe, but a summary has already been printed in the Russian language [6], and the pertinent part of this has been kirdly translated for us by D. K. KAZARNOFF, Instructor in Mathematics at the University of Michigan. To quote from this report:

"The expedition of SS Sedor, as well as the North Pole Station, were functioning since the establishment of the present Russian network of meteorological stations. This circumstance has per mitted the drawing of isobars, lines of equal pressure, for the Arctic Basin on the basis af actugl observations, and not on the basis of a theoretical hppothesis that was in use before the rear 1937 . (Our italics.)

"In this regard the drift of the Sedov was especially instructive. For the period 1937-39, Figures 3, 4, 5, 6, and 7, set forth the atmospheric-pressure charts for the Arctic Basin for each season during that period. These charts were prepared by B. L. DZRDZEEVSKY, making use of 

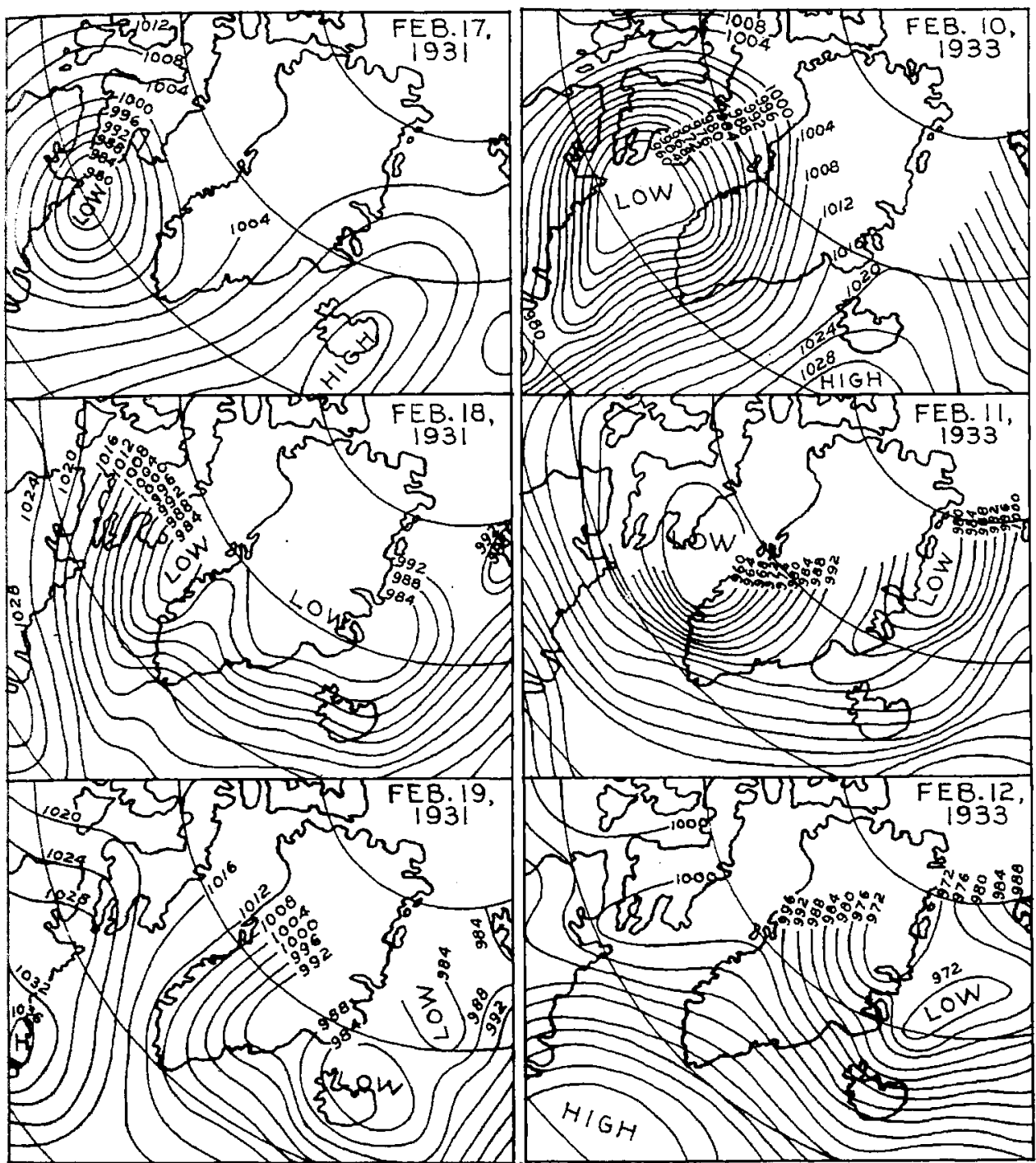

Fig. 7--Series of daily synoptic charts by British Air Ministry for the Greenland Area when cyclones approached west coast

the synoptic data from North Pole Station and Sedov.

"From these charts one sees how different the synoptic situation is for the different seasons. The usual hrpothesis of a constant polar anticrclone breaks down in the light of the observations of the North Pole Station and Sedov. During the summer season, July and August, there is a region of lower pressure north of the nearer part of the Arctic region," (Italics in the original.)

The point of greatest interest in this summary statement ts that in the chart to show mean annual air-pressure the isobar of $1013 \mathrm{mb}$ surrounds the central Polar Basin, with no other isobar within it--hence the Polar Basin is a region of marked mean normal atmospheric pressure, exactly $2 s$ was foreshadowed by the earlier and less complete data.

The popular narrative account of the drift of the North Pole Station [7] has offered further confirmation of this conclusion. To the north of $80^{\circ}$ (May 21 to December 24, 1937) the wind-force varied from complete calm to occasional light winds, usually insufficient to turn the windmill used to charge the batteries. The air-temperatures were uncomfortably warm and accompanied by so much meiting of the floe that beds and other furnishings had to be shored up. These conditions 
continued until the floe had drifted to $80^{\circ}$, where suddenly the orbit of the Greenland anticyclone was entered (see Fig. 6). From here southward almost incessant hurricanes from the west prevailed. To quote PAPANIN: "Damn the wind! It blows and blows incessantly. We must be drifting through an area of endless winds. Greenland is letting us know where it stands" (p. 229). Later he wrote: "The wind has been blowing constantly ever since we got into Greenland waters. The blizzard has made hermits of us. "We stay inside the tent like badgers in their lairs" (p. 236).

In the full light of this new knowledge concerning the meteorology of the Polar Basin the wholly unsupported theory of the Polar Basin anticyclone (BJERKNES) must be given up and be replaced by recognition of the fact that it is an area of normal atmospheric pressure. The so-called polar front northwest of Europe (the original one of the theory) is the Greenland anticyclone front, and this involves a shift of the fixed anticyclone southward by some 700 miles along the meridian of $40^{\circ}$ west. In 1926 the senior author wrote in Glacial anticyciones:

". . it is apparent that the author's studies of the Greenland glactal anticyclone are in complete harmony with those of BJERKNES and SOLBERG of the cyclone families in Europe. The one theory is fitted to the other as are the teeth of geared wheels. Alone the cold air which rejuvenates the dying cyclones on their approach to the coast of Europe from the west, instead of having a polar origin, issues from the Greenland Continent, during a stroph of the anticyclone" (p. 155).

The extensions of the "polar front" from its original position have little in common with the Greenland front. They are shifting fronts of cyclogenesis to cold air-masses, with no similar fixed feeding area from higher levels comparable to that of Greenland.

To illustrate the errors of the synoptic charts of the Greenland Area we have chosen two periods when a cyclone approached the west coast of Greenland (see Fig. 7). They are in no sense exceptional and they were chosen because the dates fall within periods from which exceptionally full and reliable data are now avallable, though these were only in part available when the charts were issued. The maps of Figure 3 show the meteorological and aerological Greenland stations which were functioning during these periods. The operation is a post-mortem one performed long after the cyclones had died. The actual paths of the cyclones are given in Figure 8. It will be noted that instead of making the transection of Greenland the cyclones were switched up Davis Strait along the border of the anticyclone. The series of 1931 was studied by GEORGI, who wrote of it:

"With' the disposable material, i.e., the paper of Mr. MRRLEES, observations placed at my disposal by W. H. HOBBS and by the Danish Meteorological Institute, I have compiled the weather maps of the Deutsche Seewarte for the weather periods. . . . The center of every low is signified by the date. . . . It is seen that the tracks have apparently been modified by the existence of the Greenland Continent. . . . the stationary lows of the Davis Strait, whose normal eastward movement is stopped there." [Greenland as a switch for cyclones, Geog. I." v. 31, p. $344,1933$.

On the chart for 1931 one low (21) is represented at the Ice Cap Station as though it had really invaded the anticyclone. This chart was prepared in 1933, a year before the full data from that station had been made available. The pressure-diagram for Ice Cap Station now published [8] in. dicates no low-pressure area there on February 21 (see Fig. 9).

The cyclones of February, 1933, have been studied in the same manner by the junior author, who has written of them [9]:

"From these [observations] for the month of February, 1933, the month having the largest number and the most severe of our storms, a chart was prepared (Fig. 6) showing the location of the center of each low-pressure area. This one was the method employed by GEORGI and the diagram thus prepared using the February data is another proof of his contention that Greenland acts as a 'switch for cyclones'. The chart shows the location of the centers from day to day, but more important here is the fact that of over 30 cyclones thus located only one may have crossed the ice-cap and that one in the southernmost part of Greenland. It also indicates that practically all the lows move up along either the west or the east coast; very often there are separate disturbances moving up each coast simultaneously.

".. This anticyclonic condition, the 'glacial anticyclone' of HOBBS, is the mechanism that really acts as the 'switch' described by GEORGI." [See also 10.] 


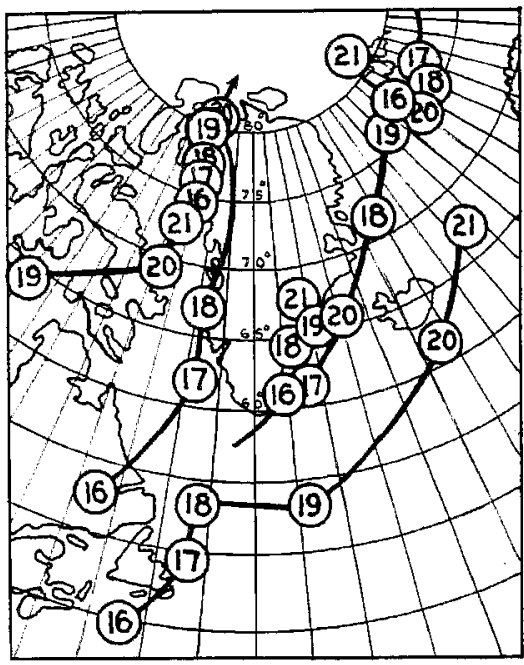

1931

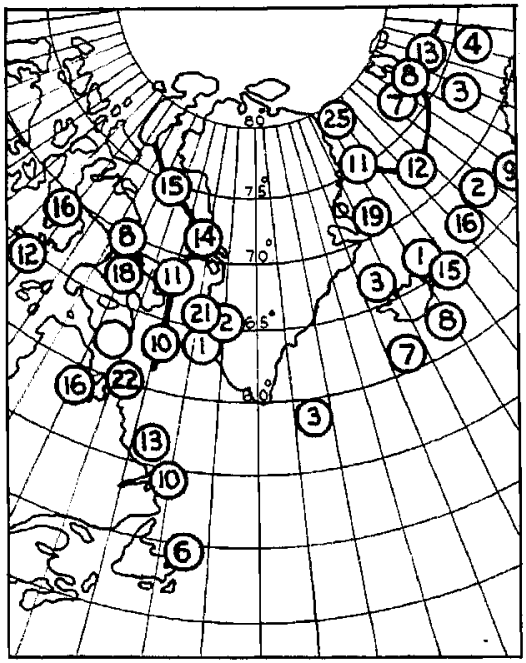

1933

Fig. 8--Actual paths of cyclones represented on the synoptic charts of Figure 7

The junior author has prepared "post-mortem" synoptic weather-charts corresponding to the middle date in each of the series of Figure 9, but with use of the fuller data now available (see Fig. 10). It may be confidently asserted that all charts of the area must conform to this general pattern so far as Greenland itself is concerned. In the brief summer season strong cyclones from the west will impinge upon its western coast in some places through a marginal strip of as much as 100 miles, but in winter not at all. This has been proven by the German observations made at Weststation in latitude $71^{\circ}[10]$.

What finally becomes of the cyclones when they have arrived at the Greenland West Coast? It is highly probable that they pass into the upper-air currents which feed the anticyclone. The junior author has shown (loc. cit.) that at his Peary Lodge Station on the Greenland West Coast in latitude $73^{\circ} .5$, the lows which approach from the west are accompanied by the same changes as those associated with a warm front. Most characteristic is the cloud-sequence. This is from cirrus through eirro-stratus, alto-stratus, stratus, and finally precipitation with nimbo-stratus. The warm front of the low thus appears to ride up over the outflowing air of the anticyclone so that much of its moisture is precipitated there as it goes into occlusion. A partial parallel may be seen on the Pacific Coast of North America where the lows off the ocean meet the coastal mountain ranges.

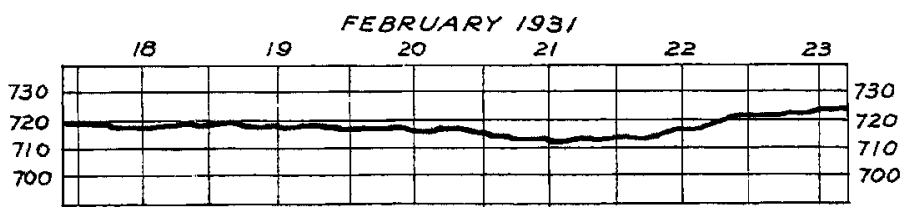

Fig. 9--Pressure-diagram for February dates in 1931 at Ice-Cap Station (after Mirrlees)

\section{References}

[1] WILLIAM H. HOBBS, The glacial anticylone, the poles of the atmospheric circulation, with an introduction by HUGH ROBERT MILL, Macmillan, 198 pp., 1926.

[2] In latitude $71^{\circ}$ north, compare R. HALZAPPEL, Wiss. Ergebn. Deutsch. Grönl.-Exped. A. Wegener 1929 u. 1930-31, จ. 4, Part II, p. 248, 1935; also KURT WEGENER, ibid., จ. 7, pp. $4-31,1940$. 


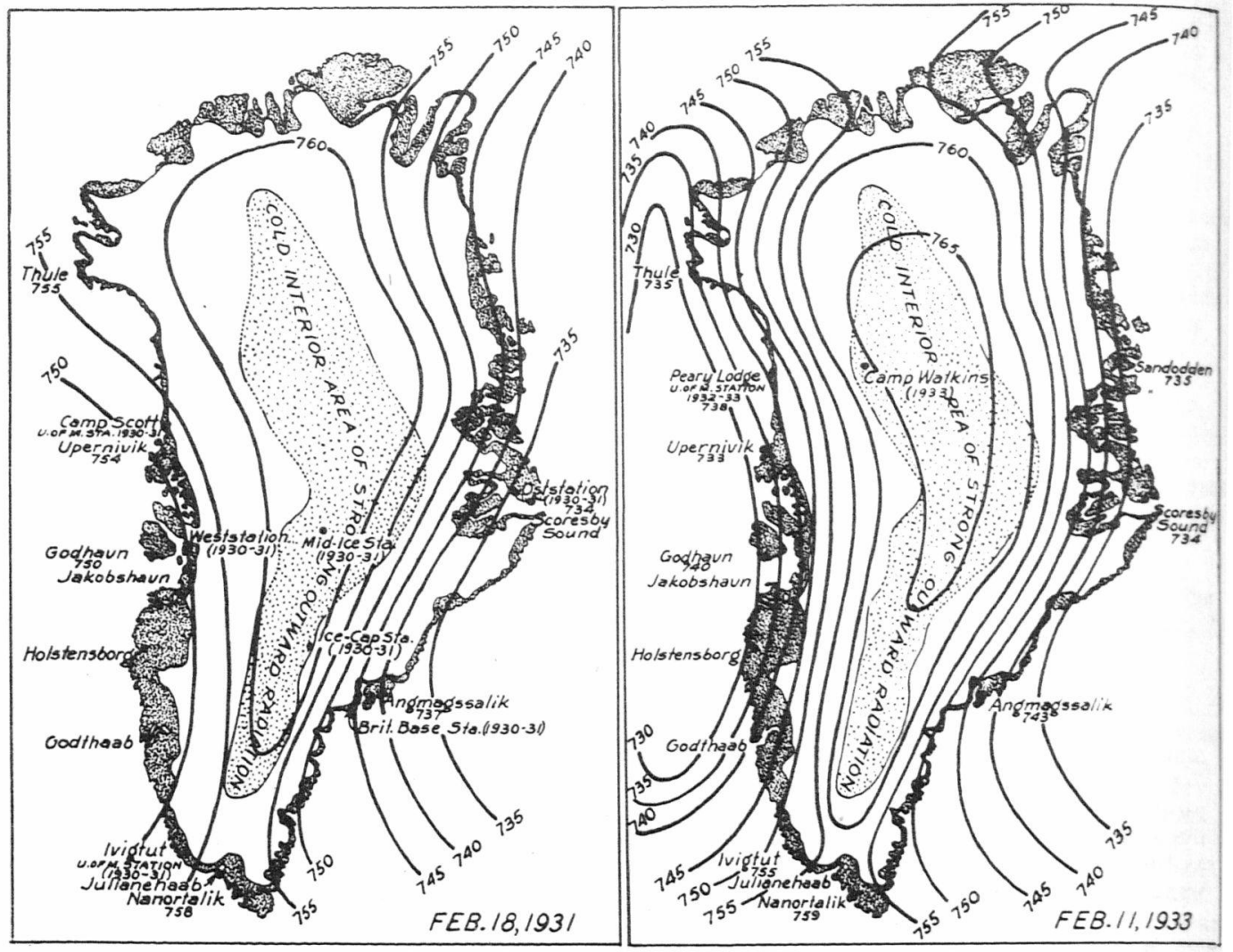

Fig. 10-- "Post-mortem" weather charts of the Greenland Area for February 18, 1931, and February 11, 1933 (these should be compared with those of Figure 7)

[3] J. GEORGI, Greenland as a switch for cyclones, Geog. J., v. 31, p. 344, 1933; R. L. BELKNAP, Meteorological report of the University of Michigan-Pan American Airways Greenland Expedition, August 1, 1932-July 31, 1933, Rep. Greenl. Exped. Univ. Mich., Sci. Ser., v. 6, Part II, pp. 194-195, 1941; WILIIAM H. HOBBS, Nourishment of the Greenland Continental Glacier, J. Geol., v. 52, No. 2, pp. 73-83, 1944.

[4] See J. Geol., v. 52, pp. 74-75, 1944.

5. The glacial anticyclones, Chap. 3 and 10, map on p. 149.

6 6. S. BADIGIN, Over the Arctic Ocean on the ship Sedov (in Russian), 1940.

[7] IVAN PAPANIN, Life on an ice floe, diary of Ivan Papanin (translated from the Russian), Julian Messner, Inc., New York, 300 pp., illus., 1939.

[8] MiRRLEeS, loc. cit., PI. XI.

19] RALPH L. BELKNAP, Meteorological report of the University of Michigan-Pan American Air ways Greenland Expedition, August 1, 1932-July 31, 1933, Rep. Greenl. Exped. Univ. Mich., Sci. Ser., v. 6, Part II, pp. 194-195, 1941.

[10] WILIIAM H. HOBBS, J. Geol., v. 52, pp. 77-83, 1944.

Department of Geology, University of Michigan, Ann Arbor, Michigan 